\title{
Kısmi Gölgelenme Şartları Altındaki Kompleks Yapılı Fotovoltaik Enerji Sistemlerinde Maksimum Güç Noktası Takibinin Metasezgisel Algoritmalar Kullanılarak İncelenmesi
}

\author{
Ayşenur Özdemir ${ }^{1}$, Nihat Pamuk ${ }^{2 *}$ \\ ${ }^{1}$ Zonguldak Bülent Ecevit Üniversitesi, Mühendislik Fakültesi, Elektrik Elektronik Mühendisliği Bölümü, Zonguldak, Türkiye, (ORCID: 0000-0002-9614-1603) \\ ayozdemir28@gmail.com \\ ${ }^{2^{*}}$ Zonguldak Bülent Ecevit Üniversitesi, Mühendislik Fakültesi, Elektrik Elektronik Mühendisliği Bölümü, Zonguldak, Türkiye, (ORCID: 0000-0001-8980-6913) \\ nihatpamuk@gmail.com
}

(First received 8 October 2021 and in final form 23 December 2021)

(DOI: $10.31590 /$ ejosat.1006248)

ATIF/REFERENCE: Özdemir, A. \& Pamuk, N. (2021). Kısmi Gölgelenme Şartları Altındaki Kompleks Yapılı Fotovoltaik Enerji Sistemlerinde Maksimum Güç Noktası Takibinin Metasezgisel Algoritmalar Kullanılarak İncelenmesi. European Journal of Science and Technology, (31), 157-164.

$\ddot{\mathbf{O} z}$

Fotovoltaik (PV) enerji sistemlerinin verimlilik değerini arttırabilmek oldukça önemlidir. Bunun için güç elektroniği çeviricilerinin verimli çalışacak şekilde tasarlanması gerekmektedir. Buna ek olarak maksimum güç noktası takibide verimlilikte önemli kazanç sağlayabilmektedir. Geleneksel algoritmalar maksimum güç noktası takibi yapılırken, eşit dağılımlı 1şıma ve sıcaklık şartları altında oldukça verimli bir şekilde çalışmaktadır. Ancak kısmi gölgelenme şartları meydana geldiğinde, geleneksel takip yöntemleri global maksimum güç noktasını izleyememekte ve yerel maksimum güç noktalarına yakalanmaktadır. Buna karşılık doğadan ilham alınarak oluşturulan metasezgisel algoritmalar global maksimum güç noktasının takip edilmesinde daha başarılı olmaktadırlar. Bu çalışmada kompleks yapıya sahip PV enerji sistemlerinde, maksimum güç noktasının takibinde kullanılan çalışmalar hakkında detaylı bilgiler verilmiştir. Kısmi gölgelenme şartları altındaki PV enerji sistemlerinde, sıcaklık ve ışınım miktarının sistem üzerindeki etkisinden bahsedilmiştir. Çalışmada maksimum güç noktası takip yöntemleri hakkında bilgiler verilmekte olup, geleneksel ve metasezgisel yöntemlerin uygulanan kriterler bakımından birbirleri ile karşılaştırmalı analizi verilmiştir. PV enerji sistemlerinde kullanılan metasezgisel algoritmalardan biri olan Parçacık Sürü Optimizasyon (PSO) algoritmasıyla ile ilgili çalışmalar incelenmiştir. Maksimum güç noktası takip yöntemleri arasında sıklıkla kullanılan ve popüler bir algoritma olan PSO algoritması ile, sistemin maksimum güç noktası takibi yüksek doğruluk oranında izlenebilmektedir.

Anahtar Kelimeler: Fotovoltaik enerji sistemleri, Kısmi gölgelenme, Metasezgisel algoritmalar, Maksimum güç noktası takibi.

\section{Investigation of Maximum Power Point Tracking in Complex Photovoltaic Energy Systems Under Partial Shading Conditions Using Metaheuristic Algorithms}

\begin{abstract}
It is very important to increase the efficiency value of photovoltaic (PV) energy systems. For this, power electronics converters must be designed to work efficiently. In addition, maximum power point tracking can provide significant gains in efficiency. Conventional algorithms work very efficiently under evenly distributed radiation and temperature conditions while tracking the maximum power point. However, when partial shading conditions occur, traditional tracking methods cannot follow the global maximum power point and are caught in the local maximum power points. On the other hand, metaheuristic algorithms inspired by nature are more successful in tracking the global maximum power point. In this study, detailed information is given about the studies used in the follow-up of the maximum power point in PV energy systems with complex structure. In PV energy systems under partial shading conditions, the effect of temperature and radiation amount on the system is mentioned. In the study, information about maximum power point tracking methods is given, and a comparative analysis of traditional and metaheuristic methods with each other in terms of applied criteria is given. Studies on the Particle Swarm Optimization (PSO) algorithm, which is one of the metaheuristic algorithms used in PV energy systems, are examined. With the PSO algorithm, which is a popular and frequently used algorithm among the maximum power point tracking methods, the maximum power point tracking of the system can be monitored with high accuracy.
\end{abstract}

Keywords: Photovoltaic energy systems, Partial shading, Metaheuristic algorithms, Maximum power point tracking.

* Corresponding Author: nihatpamuk@gmail.com 


\section{Giriş}

Günümüzde nüfus artışı ile birlikte enerjiye olan ihtiyacın artması, kömür, petrol, doğal gaz gibi fosil yakıtların yakın gelecekte tükenecek olması düşüncesi, çevresel kaygılar ve enerjide dışa bağımlılığı en aza indirmek gibi temel nedenler üretimde alternatif, temiz ve yenilenebilen enerji kaynaklarının arayışlarına sebep olmuştur. $\mathrm{Bu}$ durum yenilenebilir enerji kaynaklarının önemini arttırmıştır. Jeotermal, hidroelektrik, rüzgar, biokütle, dalga ve güneş enerjisi yenilenebilir enerji kaynaklarından bazılarıdır. Güneş enerjisi yenilenebilir enerji kaynakları arasında en yaygın olarak tercih edilmektedir. Güneşten elde edilen enerjiyi PV modüller aracılığıyla doğrudan elektrik enerjisine dönüştürebilme özelliği sayesinde, güneş enerjisi elektrik enerjisi üretiminde sıklıkla kullanılan bir kaynaktır (Bholane, \& Babu, 2018).

PV enerji sistemleri temiz, düşük bakım maliyeti, gürültüsüz ve modüler yapısı ile düşük güç değerlerinden daha yüksek güç değerlerine kadar kolaylıkla tasarlanabilir ve uygulanabilir olması başlıca avantajları arasında sayılmaktadır (Ünlü, 2015). Geçmişte güneş enerjisi dönüşüm sistemleri tek başına belirli bir yükün enerji gereksinimini karşılamak amacıyla kullanılmıştır. Ancak zaman ilerledikçe güneşten gelen sıcaklık ve 1şıma miktarının sürekliliğinin sağlanamaması, günün her saatinde yükün enerji gereksiniminin olması nedeniyle başka çözüm yolları aranmaya başlanmıştır. Bunun sonucunda da batarya depolama sistemleri geliştirilmiştir (Çetinbaş, Tamyürek, \& Demirtaş, 2019).

Günümüzde, farklı yenilenebilir enerji kaynaklarının güneş enerjisi ile birlikte kırsal yerlerde ve şebekelerde hibrit bir şekilde kullanımı giderek artan bir uygulama alanı olmaya başlamıştır. $\mathrm{Bu}$ durum mikro şebekeler olarak isimlendirilen sistemlerin ortaya çıkmasına neden olmuştur. Mikro şebekeler ile enerjinin yerinde üretimi ve tüketimi faydalarına ilave olarak, yenilenebilir enerji kaynaklarının üretmiş olduğu elektrik enerjisinin enerji üretim santrallerinin bulunduğu coğrafi bölge şartlarına göre ayarlanabilmesine olanak sağlamaktadır. Bu yüzden mikro şebekelerden en yüksek seviyede verim alabilmek için, mikro şebekelerde kullanılan PV enerji modüllerinin ve diğer bileşenlerinin kullanılması, teknik ve ekonomik açılardan incelenmesi ve optimizasyonunun gerçekleştirilmesi büyük önem kazanmaktadır (Çetinbaş, Tamyürek, Demirtaş, 2019).

PV enerji sistemleri şebeke bağlantı yapısı ve maliyetleri incelendiğinde maksimum verimle çalışması beklenen kompleks sistemlerdir. Fotovoltaik modülün çalışma noktası, yük direncine yani çalışma akımı ve çalışma gerilimine bağlıdır. Bu sistemleri maksimum verimde çalıştırabilmek için maksimum güç noktası takibi (MGNT) adı verilen uygulamaların kullanılması gerekir. MGNT, güneş panellerinin güneş 1şınlarını takip etmelerini sağlamak amacıyla yazılımsal olarak geliştirilmiş algoritmalar ile, güneş panelinin çalışma noktasını değiştiren elektronik aygıtlardır (Karagöz, 2020). MGNT algoritmalarının çalıştırılması esnasında güç elektroniği dönüştürücüleri ve PV modüllerden elde edilen enerjinin mikrodenetleyiciler aracılığıyla yüke aktarılması sağlanır.

Literatürde pek çok MGNT algoritması vardır, ama her MGNT algoritması temelde verilen bir fonksiyonun maksimum çalışma noktasını bulan bir optimizasyon algoritmasıdır. Bundan dolayı sistemde kullanılan MGNT algoritmalarının hassasiyeti ve doğruluk hızı araştırma yöntemleri arasında bulunmaktadır
(Anoop, \& Nandakumar, 2018). PV sistemlerin, MGNT uygulamalarında karşılaştığı en büyük sorunlardan biri kısmi gölgeleme durumudur. Hareket eden bulutlar, ağaç ve bina gibi yapıların gölgesi panelde kısmi gölgelemeye neden olur. $\mathrm{Bu}$ sebeple kısmi gölgeleme şartları da göz önüne alınarak PV sistemlerden maksimum verim almak için farklı tasarımlar ve algoritmalar ile sistemler gerçekleştirilmektedir.

MGNT yöntemleri geleneksel ve meta sezgisel yöntemler olarak ikiye ayrılmıştır. Geleneksel MGNT algoritmalarına örnek olarak Değiştir ve Gözle (D\&G), kısa devre akımı, artımsal iletkenlik, açık devre gerilimi yöntemleri kullanılmaktadır. Bu algoritmalar eşit dağılımlı ışıma ve sıcaklık şartlarında maksimum güç noktasını iyi bir şekilde takip etmektedirler. Fakat kısmi gölgeleme şartları altında MGNT'nin doğruluk değerine ulaşılamayabilir. Çünkü PV modüller kısmi gölgeleme şartları altında güç gerilim karakteristik eğrisinde birden çok yerel maksimum güç noktasına ve bir tane global maksimum güç noktasına sahip olacaktır. Bu nedenle geleneksel yöntemler yerel maksimum güç noktalarına yakalanıp global maksimum güç noktasını izlemede başarısız olmaktadır. $\mathrm{Bu}$ probleme çözüm yolu olarak meta sezgisel tabanlı algoritmalar geliştirilmiştir (Manickam, Raman, Raman, Ganesan, Nagamani, 2016).

Meta sezgisel algoritmaların formülasyonlarında yerel maksimum güç noktalarından uzaklaşmalarına imkan veren olasılıksal değişkenler kullanılmaktadır. $\mathrm{Bu}$ nedenle genellikle yerel maksimum güç noktalarına yakalanma problemleri ile karşı karşıya kalınmakta ve bunlara çözüm üretilmektedir (Fang, \& Lian, 2017). Meta sezgisel algoritmalara örnek olarak Parçacık Sürü Optimizasyonu (PSO), Guguk Kuşu Optimizasyon algoritması (GKO), Yapay Arı Kolonisi algoritması, Karınca Koloni Optimizasyonu, Ateşböceği algoritması gibi çeşitli algoritmalar verilebilir. Günümüzde PV enerji sistemlerinde MGNT metotları üzerine sayısız çalışmalar yapılmıştır. Basit, maliyeti düşük, yüksek performanslı ve hızlı bir MGNT yöntemi keşfetmek amacıyla araştırma - geliştirme çalışmaları devam etmektedir.

Miyatake ve arkadaşları tarafindan yapılan çalışmalarda kısmi gölgeli koşullar altında Parçacık Sürü Optimizasyonu (PSO) yaklaşımı kullanılarak yeni bir MPPT algoritması önerilmiştir. Önerilen algoritma, birden çok PV dizisini kontrol etmek için yalnızca bir çift sensör kullanmaktadır. Bu durum uygulama açısından basitlik, daha düşük maliyet ve daha yüksek verimlilik sunmaktadır (Miyateke, Verachary, Toriumi, Fujii, \& Ko, 2011). Shaiek ve arkadaşları tarafından yapılan çalışmada, kısmi gölgeleme şartları altında DC-DC yükselticilerle bağlanan ve farklı tekniklerle kontrol edilen PV enerji sistemleri Matlab/Simulink yazılımı kullanılarak gerçekleştirilmiştir. D\&G ve Artımlı İletkenlik algoritmalarının kısmi gölgeleme koşulları altında MPP'yi takip etmede başarısız olduğu sonucuna ulaşmışlardır (Shaiek, Ben Smida, Sakly, \& Mimouni, 2013).

Benyoucef ve arkadaşları tarafından yapılan çalışmada, yeni bir yapay Arı Kolonisi tabanlı MPPT önerilmiştir. Önerilen yöntemin etkinliğini doğrulamak ve değişen hava koşullarında performansını izlemek için PSO tabanlı MPPT algoritması ile karşılaştırmalar yapılmıştır. Ayrıca önerilen yöntemi deneysel olarak doğrulamak için bir laboratuvar kurulumu gerçekleştirilmiştir (Benyoucef, Chouder, Kara, Silvestre, \& Sahed, 2015). Kaced ve arkadaşları tarafindan yapılan çalışmada, Yarasa Algoritması kullanarak kısmi gölgeleme koşulları altında PV enerji sistemleri için bir MPPT algoritması 
önerilmiştir. Önerilen yöntemin performans analizi Matlab/Simulink yazılımı kullanılarak gerçekleştirilmiştir. Ek olarak D\&G ve PSO yöntemleriyle karşılaştırma yapılmıştır (Kaced, Larbes, Ramzan, Bounabi, \& Dahmane, 2017).

Abo-Elyousr ve arkadaşları tarafından yapılan çalışmada, Guguk kuşu Algoritması ve PSO algoritmalarını önerilmiştir. Sistemin programlama ve modelleme yapısı Matlab/Simulink yazılımı kullanılarak gerçekleştirilmiştir. Elde edilen sonuçları D\&G algoritması ile karşılaştırılmıştır (Abo-Elyousr, Abdelshaf, \& Abdelaziz, 2018). Aygül ve arkadaşları tarafından yapılan çalışmada, kısmi gölgeleme koşulları altında MPPT' nin izleme hızını iyileştirmek amacıyla Kelebek Optimizasyon Algoritmasını (KOA) kullanılmıştır. Tasarlanan model yapısı üzerinde Matlab/Simulink yazılımı kullanılarak, üç farklı gölgeleme durumu için benzetim çalışması yapılmıştır. Elde edilen sonuçlar PSO, Gri Kurt Optimizasyon Algoritması (GKOA) ve Yerçekimi Arama Algoritması (YAA) kullanılarak karşılaştırılmıştır (Aygül, Cikan, Demirdelen, \& Tumay, 2019).

Motamarri ve Nagu tarafindan yapılan çalışmada, global MPPT için PSO algoritmasına dayalı hibrit bir yazılım (VPSOLF) önerilmiştir. Önerilen yöntem Matlab/Simulink yazılımı kullanılarak gerçekleştirilmiştir. Elde edilen sonuçlar deneysel olarak doğrulanmıştır (Motamarri, \& Nagu, 2020). Charin ve arkadaşları tarafından yapılan çalışmada ise, doğadan esinlenilmiş kontrol algoritmasının hibrit yapısı önerilmiştir. Önerilen algoritma yapısında, global MPP'yi elde etmek için Levy Uçuş Optimizasyonu (LUO) ve PSO'nun hibrit bir modeli kullanılmıştır. Elde edilen sonuçlara dayanılarak, hibrit yapıdaki LPSO algoritmasının yerel ve global maksimum güç noktasını etkin bir şekilde takip ettiği gösterilmiştir (Charin, Ishak, Zainuri, Ismail, \& Jamil, 2021).

\section{Fotovoltaik Enerji Sistemleri}

Fotovoltaik etki, güneş panelleri yardımıyla 1 şı enerjisini doğrudan elektrik enerjisine dönüştürülmesi işlemine denir. İlk defa 1839 yılında Alexandre Edmond Becquerel tarafindan bu kavram ortaya atılmıştır. Becquerel bu kavramı, sıvı bir elektrolit çözeltiye batırılmış katı elektrot üzerine düşen 1şı̆̆ın elektrotun uçlarında gerilim meydana getirdiğini saptayarak açıklamıştır. PV enerji sistemleri, farklı ihtiyaç taleplerine ve uygulamalarına göre birçok şekilde tasarlanabilir. Sistem bileşenleri güneş panelleri, batarya (akü), invertör, şarj regülatörü ve bir kısım elektronik destek devrelerinden meydana gelmektedir.

Güneş panellerinin üzerine güneş 1şığının düşmesiyle birlikte üretilen doğru akım büyüklüğü, sistem içerisinde farklı topolojilerde bulunabilen DC-DC dönüştürücüler vasıtasıyla sağlanır. Sağlanan bu akım eviriciler aracılığıyla alternatif akıma (AC) çevrilerek kullanıma sunulmaktadır. PV sistemler genellikle şebeke bağlantısız (off-grid), şebeke bağlantılı (ongrid) veya karma (hybrid) olmak üzere üç farklı grupta incelenmektedir.

\subsection{Fotovoltaik Hücrenin Eşdeğer Devre Modeli}

Tek diyotlu eşdeğer devre modeli, basitliği sebebiyle bir PV modül için en yaygın kullanılan modeldir. Devrede bir akım kaynağı (Iph), bir diyot, paralel bağlı (Rp) bir direnç ve seri bağlı bir dirençten (Rs) meydana gelmektedir (Nugraha, Lian, \& Suwarno, 2019). Şekil 1'de tek diyotlu PV hücre yapısının elektriksel eşdeğer devre şeması gösterilmiştir.

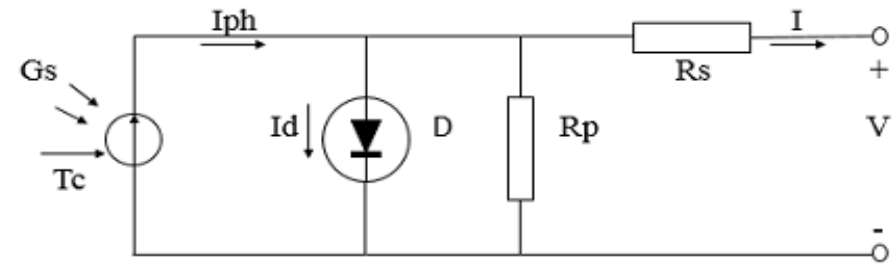

Şekil 1. Tek diyotlu PV hücre yapısının elektriksel eşdeğer devre şeması

\subsection{Farklı Işınım ve Sıcaklık Koşulları Altındaki Kompleks Yapılı Fotovoltaik Enerji Sistemlerinin İncelenmesi}

Güneş panellerini birbirine seri, paralel ya da karma yapıda bağlayarak güç çıkışını arttırmak mümkündür. $\mathrm{Bu}$ şekilde oluşturulan sistemlere kompleks yapılı PV enerji sistemi denir. Bir PV modülden alınabilecek maksimum gücü belirleyen iki önemli etken güneş 1şınımı ve sıcaklıktır. PV modülden üretilen güç, modül akımı ve gerilimi çarpılarak hesaplanır. PV sistemlerde verimliliğin değerlendirilmesinde standart bir test koşulu bulunmaktadır. PV panellerin kataloglarında genelde bu standart test koşullarındaki değerler yer almaktadır.

PV panellerin güç-gerilim karakteristik eğrisinde belirli bir gerilim ve akım değerlerine karşılık sağlanan maksimum güç noktası standart test koşullarında $1000 \mathrm{~W} / \mathrm{m} 2$ değerindedir. Işınım ve sıcaklık değeri ise $25^{\circ} \mathrm{C}$ modül sıcaklığı olarak tanımlanır. Fakat her zaman bu şartlar oluşmayabilir. PV modülün çıkış akım ve gerilim değerleri de bu durumdan etkilenir (Suryavanshi, Joshi, \& Jangamshetti, 2012). Şekil 2'de 260 W gücüne sahip PV modülün farklı 1şınım değerleri altındaki güç-gerilim karakteristik eğrileri gösterilmiştir. Şekil 3'te $260 \mathrm{~W}$ gücüne sahip PV modülün farklı ışınım değerleri altındaki akım-gerilim karakteristik eğrileri gösterilmiştir.

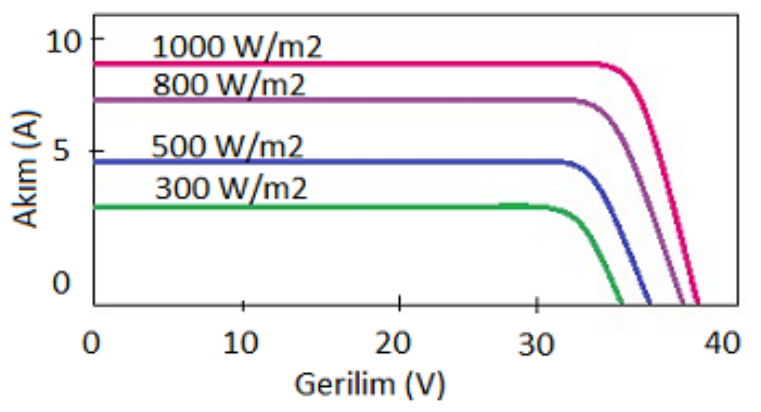

Şekil 2. Farklı ışınım değerleri altında PV hücre modülüne ait güç-gerilim karakteristik eğrileri

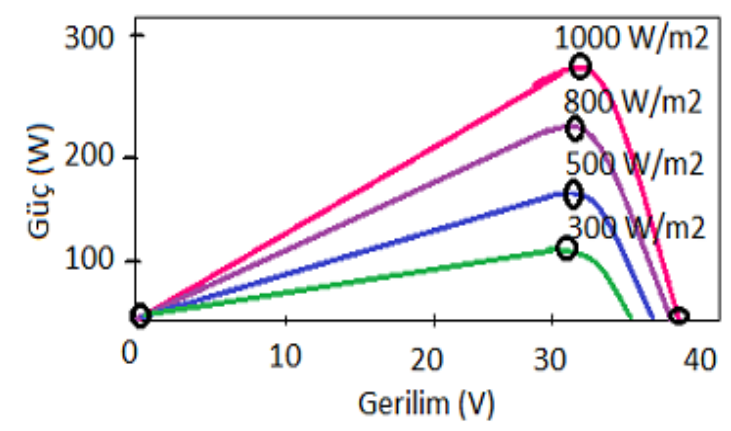

Şekil 3. Farklı ışınım değerleri altında PV hücre modülüne ait akım-gerilim karakteristik ĕgrileri 
PV modülün sabit sıcaklık altındayken ışınım miktarının artması çıkış akımını artırmaktadır. Böylece PV sistemin maksimum çıkış gücü, akım değerindeki değişimden doğrudan etkileneceği için 1şınım miktarındaki artış, çıkış gücününde artmasına neden olmaktadır. Şekil 4'te farklı sıcaklık değerleri altındaki aynı PV modül hücresinin güç-gerilim karakteristik eğrileri verilmiştir. Şekil 5'te farklı sıcaklık değerleri altındaki aynı PV modül hücresinin akım-gerilim karakteristik eğrileri verilmiştir.

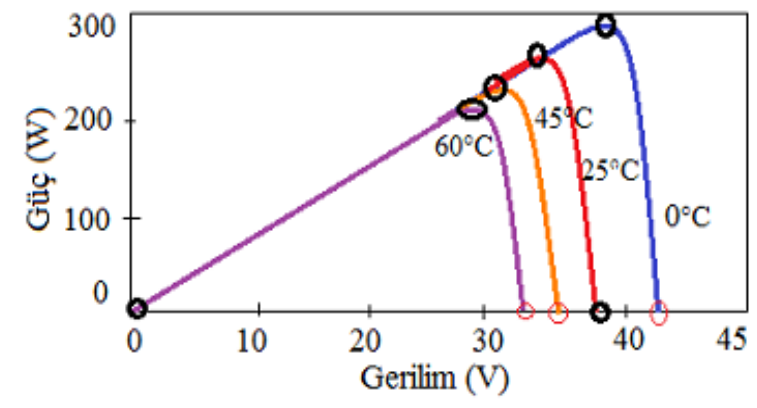

Şekil 4: Farklı slcaklık değerleri altında PV hücre modülüne ait güç-gerilim karakteristik eğrileri

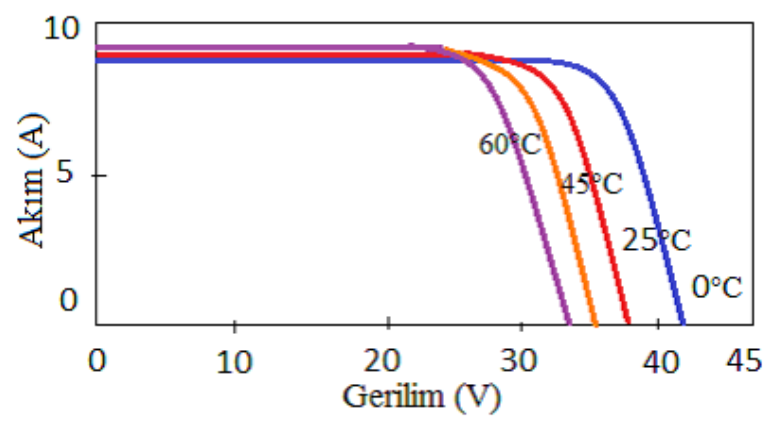

Şekil 5: Farklı sıcaklık değerleri altında PV hücre modülüne ait akım-gerilim karakteristik eğrileri

PV modülün sabit 1şınım altındayken sıcaklık değerinin artması çıkış gerilimi değerini azaltmaktadır. Böylelikle PV enerji sisteminin maksimum çıkış gücü, gerilim değerindeki azalmadan doğrudan olarak etkilenmekte ve sicaklık değerindeki artış, çıkış gücü değerinin azalmasına sebep olmaktadır.

\section{Materyal ve Metotlar}

\subsection{Kısmi Gölgeleme Koşullarının PV Enerji Sistemlerine Etkisi}

PV panel, sıcaklığın $25^{\circ} \mathrm{C}$ ve güneş ışınımının $1000 \mathrm{~W} / \mathrm{m} 2$ olduğu standart test koşullarında tek bir maksimum güç noktasına ulaşılır. Maksimum güç noktası takibinde tüm panellerin aynı hava şartlarında çalıştığı durumu göz önüne alınmaktadır. Ancak bu durum her zaman doğru değildir (Anoop, \& Nandakumar, 2018). Güneş panellerinin başarımını etkileyen en önemli parametrelerden biri gölgelenme durumudur. Panelden alınacak olan güç değeri enerji üretim verimini gölgeleme şartlarına karşı daha duyarlı bir yapıya dönüştürmektedir. Güç kayb1, güneş panellerinin gölgelenme çeşidine ve gölgeli olan kısmın alanına bağlı olarak değişmektedir (Azharuddin, 2012).

PV panellerin üzerine hareket halindeki bulutların, yağmur damlacıklarının, toz parçacıklarının, ağaç dallarının, yüksek yapıların ya da diğer olası nesnelerin gölgelerinin gelmesi gibi çevresel etkenler sebebiyle kısmi gölgelenme şartları altında çalışma durumu ile karşlaşabilirler. $\mathrm{Bu}$ durumda güneş 1şınımının daha az üzerine düştüğü güneş panelleri diğer panellere göre daha az miktarda akım üretecektir. Panellerin daha az miktarda akım üretmesi, panel güç değerinde de düşüşlere neden olacaktır. $\mathrm{Bu}$ gibi durumlarda çalışmasını normal bir şekilde sürdürmeye devam eden PV panellerde üretilen yüksek akım miktarı, kısmi gölgelenme şartları altında çalışan panellere zarar vermektedir. Söz konusu zararı önlemek amacıyla her bir PV paneline paralel bağlı olacak şekilde bypass bağlı diyotlar kullanılmaktadır. Bu durumda oluşacak olan yüksek akım değeri bypass diyot devresinden geçerek kısmi gölgelenme şartları altında kalan PV panellerin zarar görmesini önleyecektir (Kandemir, 2020).

Kısmi gölgelenme şartları altında, PV sistemin güç-gerilim karakteristik eğrisinde birden çok yerel maksimum güç noktası (YMGN) ve bir tane en yüksek çıkış gücüne sahip global maksimum güç noktası (GMGN) vardır. Kısmi gölgelenme şartları sadece PV enerji sistemlerinin çıkış gücü ve çıkış gerilimi değerlerinin azalmasına etki etmemektedir. Aynı zamanda PV panellerde oluşacak olan sıcak nokta olaylarına neden olmaktadır. $\mathrm{Bu}$ durum $\mathrm{PV}$ modül hücrelerinin aşırı ısınmasına bağlı olarak fiziksel yapılarının zarar görmesine sebep olmaktadır. Bu tür istenmeyen olayları önlemek amacıyla yine her bir PV paneline paralel bağlı olacak şekilde bypass bağlı diyotlar kullanılır.

Bypass bağlı diyotlar kısmi gölgelenmenin olmadığı normal çalışma koşullarında pasif durumda olup, sistem üzerinde herhangi bir etkisi bulunmamaktadır. Ancak kısmi gölgelenme şartları altında, gölgelenmenin olduğu ilgili PV panellerindeki bypass bağlı diyot devreleri aktif hale geçerek sicak nokta durumuna karşı koruma sağlamış olurlar.

Bypass bağlı diyotlarının bu avantajlarının yanı sıra farklı sorunlar1 da bulunmaktadır. $\mathrm{Bu}$ sorunlardan biri, k1smi gölgelenme şartları altında bypass bağlı diyot devresinin çalıştığ PV panel üzerinde güç ya da enerji üretiminin gerçekleştirilememesidir. Bu durumda maksimum güç seviyesi azalmaktadır. PV enerji sisteminin güç-gerilim karakteristik eğrisinde birden fazla tepe noktası oluşmakta ve sistem karmaşık bir yapı haline dönüşmektedir (Kandemir, 2020).

\subsection{DC-DC Dönüștürücüler}

DC-DC dönüştürücüler, giriş kısmına uygulanan doğru akım gerilimini, darbe genişliğini ya da frekans değerini değiştirerek çıkış kısmına veren elektronik devrelerdir. DC-DC dönüştürücülerin çıkış gerilimi değerlerini azaltan, arttıran ve azaltan-arttıran gibi türleri bulunmaktadır. MGNT algoritmalarının başlıca amacı, dönüştürücü devresinin görev periyodunu kontrol etmektir (Behera, Behera, \& Nayak, 2018). PV enerji sisteminin maksimum güç noktasında çalışmasını sağlamanın başlıca yolu düzeneğe dönüştürücü devresi ilave etmektir.

DC-DC dönüştürücüde görev periyodunu değiştirilerek doğru akım çıkışı kontrol edilmektedir. Bu nedenle DC-DC dönüştürücüler sistemin en önemli elemanlarından biridir. Görev periyodu DC-DC dönüştürücüler arasında değişken empedans görevi göstermektedir. Çevresel şartlara göre maksimum güç noktası değiştiği durumda dönüştürücü devresi MGNT ile birlikte maksimum güç noktasını takip etmektedir (Dhivya, \& Kumar, 2017). 


\subsection{Maksimum Güç Noktası Takibi}

PV sistemlerin şebeke bağlantı yapısı nedeniyle maliyetleri yüksektir. Ayrıca PV hücrelerinden yüksek verimde elektrik enerjisi elde edilmesi hedeflenmektedir. $\mathrm{Bu}$ nedenle PV sistemler maksimum verimde kullanılması istenen sistemlerdir. Panel sıcaklığı, güneş 1şınım değeri ve yük değişimine göre PV sistemlerin maksimum güç noktası değişkenlik göstermektedir. Özellikle sistem doğrudan yüke bağlı olduğu durumda PV sistemin maksimum güç noktasında çalışmadığı görülmektedir. Bundan dolayı, PV sistemin verimliliğini artırmak ve PV panellerden maksimum gücün çekilebilmesini sağlamak amacıyla (MGNT) maksimum güç noktası takibi yöntemlerinin kullanılması gerekmektedir (Safari, \& Mekhilef, 2011).

PV enerji sistemlerden maksimum güç üretebilmek için farklı yöntemler kullanılmaktadır. Elektronik takip yöntemi bu yöntemlerden birisidir. $\mathrm{Bu}$ yöntemde, PV enerji sistemi güç değerinin maksimum olduğu noktayı bulmaktadır. Bu amaçla kullanılan metasezgisel algoritmalar, yapısındaki farklı senaryolar ile bu değeri korumayı ya da daha da geliştirmeyi hedeflemektedir. $\mathrm{Bu}$ yöntem, maksimum güç noktası takibi (MGNT) olarak isimlendirilmektedir.

Maksimum güç noktası değerini sistemde kullanılan bir yazılım algoritması ile takip etmek, sistemde gereksiz malzeme ve bakım maliyeti oluşturmayacaktır. $\mathrm{Bu}$ nedenle MGNT algoritmaları PV panel veriminin artırılmasında en uygun yöntemdir. Literatürde yürütülen AR-GE çalışmaları MGNT yöntemleri üzerinde yoğunlaşmaktadır (Santos, Antunes, Chehab, \& Cruz, 2006).

Şekil 6'da MGNT sistemini içeren PV enerji sistemine ait blok diyagramı gösterilmiştir. Bu sistemde ölçülen akım ve gerilim değerleri MGNT yöntemi içerisinde kullanılan bir algoritma sayesinde darbe genişlik modülasyonunda (PWM) görev döngüsünü ayarlamakta ve DC-DC çevirici devresinin çıkışındaki sistem tarafından denetlenmektedir. MGNT yöntemleri karmaşıklık, takip hızı, doğruluk, yöntem tanınırlığı, maliyet vb. gibi etkenler sebebiyle birbirlerinden ayrılmaktadır (Esram, \& Chapman, 2007). PV panellerin maksimum güç noktasında çalıştırılmasını sağlamak amacıyla literatürde iki temel yöntem kullanılmaktadır. Bu yöntemler geleneksel MGNT yöntemleri ve metasezgisel MGNT yöntemleridir.

Geleneksel yöntemler eşit dağılımlı güneş 1şıması ve sabit sıcaklık şartları altında maksimum güç noktası takibini doğru bir şekilde yerine getirmektedirler. Fakat kısmi gölgelenme şartları altında maksimum güç noktası takibini doğru olarak yapamayabilirler. Çünkü PV modüller kısmi gölgeleme şartları altında güç gerilim karakteristik eğrisinde birden çok yerel maksimum güç noktasına ve sadece bir tane global maksimum güç noktasına sahip olacaktır. Bu durumda geleneksel yöntemler yerel maksimum güç noktalarına yakalanıp global maksimum güç noktasını izlemede başarısız olmaktadır. $\mathrm{Bu}$ problemin çözümü için metasezgisel tabanlı algoritmalar geliştirilmiştir. Tablo 1'de geleneksel ve metasezgisel algoritmaların özelliklerinin karşılaştırılması gösterilmiştir (Karakaya, 2021).

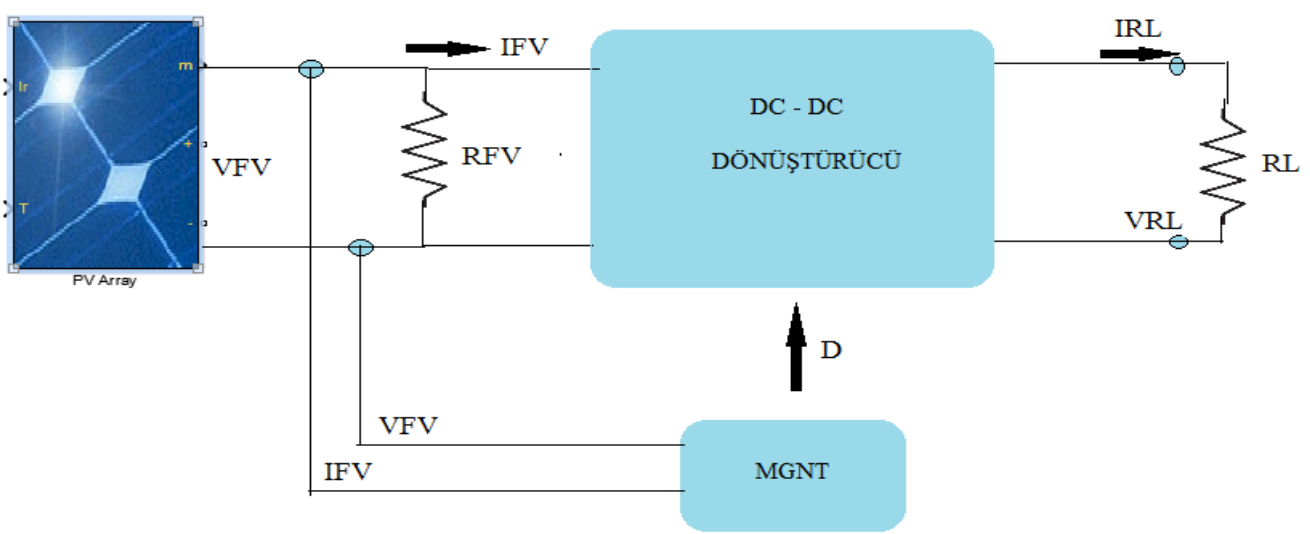

Şekil 6: MGNT sistemini içeren PV enerji sistemine ait blok diyagramı

Tablo 1. Geleneksel ve metasezgisel algoritmaların özelliklerinin karşılaştırılması

\begin{tabular}{|c|c|c|c|c|c|c|}
\hline \multicolumn{2}{|r|}{ MGNT Yöntemleri } & Parametreler & Takip Hizı & Doğruluğu & Karmaşıklık & Verim \\
\hline \multirow{4}{*}{ 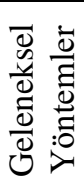 } & Değiştir \& Gözle & Akım ve Gerilim & Düşük & Orta & Düşük & Orta \\
\hline & Artan İletkenlik & Akım ve Gerilim & Düşük & Yüksek & Düşük & Orta \\
\hline & Kisa Devre Akımı & Akım ve Gerilim & Yüksek & Orta & Düşük & Düşük \\
\hline & Akım ve Gerilim Eğri Tarama & Akım ve Gerilim & Düşük & Yüksek & Düşük & Yüksek \\
\hline \multirow{6}{*}{ 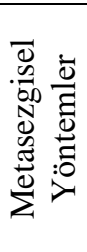 } & Genetik Algoritma & Akım ve Gerilim & Orta & Yüksek & Yüksek & Yüksek \\
\hline & Bulanık Mantık & Akım ve Gerilim & Yüksek & Çok Yüksek & Çok Yüksek & Yüksek \\
\hline & Yapay Sinir Ağları & Işınım, Akım ve Gerilim & Yüksek & Çok Yüksek & Çok Yüksek & Yüksek \\
\hline & Parçacık Sürü Optimizasyonu & Akım ve Gerilim & Yüksek & Çok Yüksek & Orta & Yüksek \\
\hline & Guguk Kuşu Arama Algoritması & Akım ve Gerilim & Yüksek & Çok Yüksek & Orta & Yüksek \\
\hline & Ateş Böceği Algoritması & Akım ve Gerilim & Yüksek & Çok Yüksek & Orta & Yüksek \\
\hline
\end{tabular}


Tablo 1'de PSO algoritması diğer algoritmalar ile karşılaştırıldığında, takip hızının yüksek, karmaşıklığının orta, doğruluğunun çok yüksek ve veriminin yüksek olduğu görülmektedir. Bundan dolayı maksimum güç noktası takibinin PSO algoritması kullanılarak yüksek doğruluk değerlerinde yapılabildiği söylenebilir (Karakaya, 2021). Fernando ve arkadaşları tarafından yapılan çalışmalarda ise, kısmi gölgelenme şartları altında PSO algoritmasıyla maksimum güç noktası takibi önerilmiştir. Önerilen yöntem iki farklı kısmi gölgelenme konfigürasyonu oluşturularak $\mathrm{P} \& \mathrm{O}$ algoritmasıyla karşılaştırılmıştır. Çalışma sonucunda PSO algoritmasının üstünlüğü gösterilmiştir (Fernando, Sergio, Fabio, \& Leonardo 2015). Badis ve arkadaşları tarafından yapılan çalışmalarda, kısmi gölgelenme şartları altında maksimum güç noktası takibini PSO algoritması ve Genetik Algoritma (GA) ile yapmışlardır. Çalışma sonucunda PSO algoritmasının GA'ya göre maksimum güç noktasını daha etkili izlediği sonucuna ulaşmışlardır (Badis, Mansouri, \& Sakly, 2016).

Genellikle metasezgisel algoritmalar sistemde karşılaşılan problemlere bağlı olarak çalışmaktadırlar. $\mathrm{Bu}$ algoritmalar sistemde bazı problemlerin çözümünde başarılı bir performans gösterirken, bazı problemlerin çözümünde ise başarısız olmaktadırlar. Bundan dolayı çok daha genel alanda uygulama şansı bulan algoritmaların geliştirilmesine yönelik çalışmalar devam etmektedir (Karaboğa, 2011). Doğal hayatta türlü canlıların davranışlarından ilham alınarak oluşturulan metasezgisel optimizasyon algoritmaları, günümüzde pek çok farklı optimizasyon çalışmasında başarılı bir şekilde uygulanmaktadır. Şekil 7'de metasezgisel tabanlı algoritmaların sınıflandırılması gösterilmiştir.

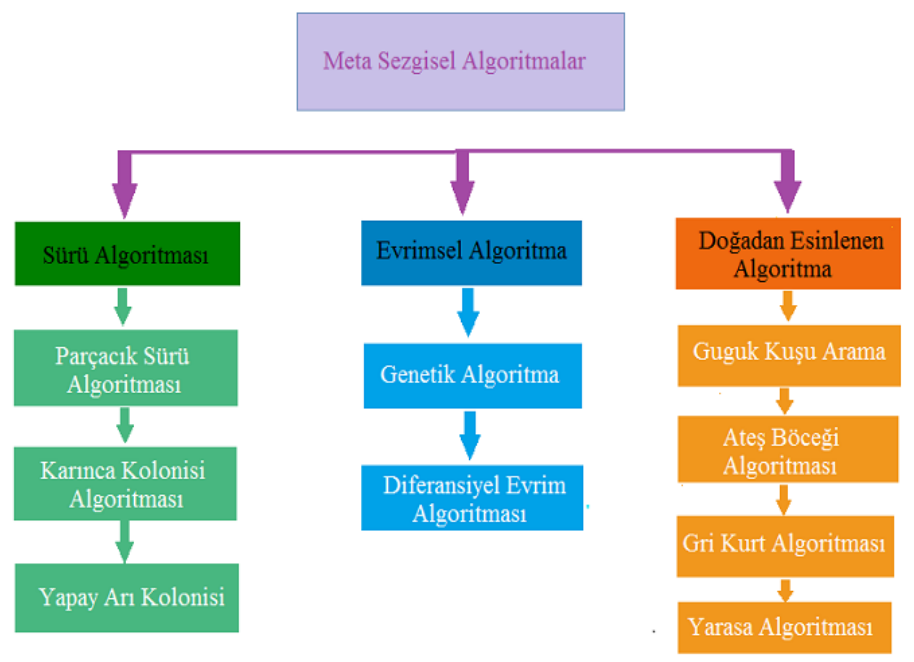

Şekil 7: Metasezgisel tabanlı algoritmaların sinıflandırılması

\subsection{Maksimum Güç Noktası Takibinde Parçacık Sürü Optimizasyon (PSO) Algoritması Kullanımı}

Parçacık Sürü Optimizasyonu, 1995 yılında Dr. Eberhart ve Dr. Kennedy tarafından geliştirilmiş, olasılıksal bir optimizasyon yöntemidir (Sun, Lou, Xi, Bao, Li, \& Yan, 2018). Sürü halinde hareket eden kuş, balık vb. gibi bazı canlıların yiyecek aramak gibi temel gereksinimleri bulunmaktadır. Canlıların söz konusu gereksinimlerini giderirken gösterdikleri hareketler sürüdeki diğer bireyleri etkilemekte ve sürünün amacına daha rahat ulaşmasını kolaylaştırmaktadır. Yapısında çok sayıda değişken ve parametre bulunduran doğrusal olmayan problemlerin çözümünde kullanılmaktadır (Kennedy, \& Eberhart, 1995). PSO algoritmasında maksimum güç noktası takibinin işlem adımları rastgele çözümlerle başlar ve fonksiyon yapısı sürekli güncellenerek en uygun maksimum güç noktası değerleri tespit edilir. PSO algoritmasının iş akış diyagramında çaprazlama ve mutasyon işlemleri olmadığından dolayı uygulama adımları oldukça kolaydır.

Optimizasyon problemlerinin çözümünde kullanılan PSO algoritması, n boyuta sahip bir arama alanındaki davranış modellerini, daha önceki davranış yapılarına bakarak incelemekte ve buna göre popülasyondaki diğer bireylerin davranış şekillerini düzenlemektedir. Arama alanındaki pozisyonu ve hızı ile belirtilen bu noktalar parçacık olarak isimlendirilirler. Popülasyon içerisindeki her bir parçacık optimizasyon probleminin çözümünü ifade eder (Azab, 2010). Şekil 8'de maksimum güç noktası takibinde kullanılan PSO algoritmasının iş akış diyagramı gösterilmiştir (Gümüş, \& Demirtaş, 2021).

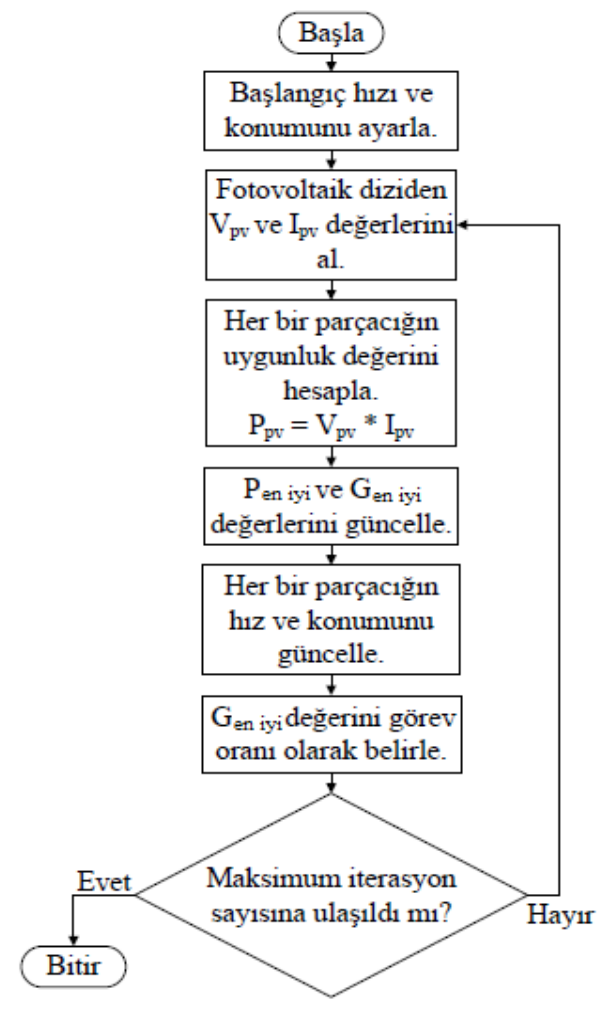

Şekil 8: PSO algoritmasının iş akış diyagramı

Diyagram incelendiğinde, PSO algoritması çalışmaya başladıktan sonra parçacıklar pozisyon ve hızlarını güncellemekte ve birbirini tekrar edecek şekilde en iyi konumunu bulmaktadır. Tüm tekrarlama adımlarında, her bir parçacık en iyi bulunan iki değer ile güncellenir. İlk değer, sürü içerisindeki her parçacığın kendi en iyi çözümüdür. Bu değer $\mathrm{P}_{\text {eniyi }}$ olarak tanımlanır. İkinci değer ise, sürüdeki tüm parçacıklar tarafindan elde edilen en iyi global çözümdür ve $G_{\text {eniyi }}$ olarak tanımlanır (Azab, 2010). Tekrarlama sırasında, sürüdeki her parçacığın bir uygunluk fonksiyonu tarafindan saptanan uygunluk değeri ile parçacığın uçuş mesafesi ve doğrultusunu saptamak için kullanılan bir hız değeri bulunmaktadır (Liu, Zhu, Tao, Wang, \& Blaabjerg, 2019). Arama işlemi esnasında, en iyi iki değer $P_{\text {eniyi }}$ ve $G_{\text {eniyi }}$ değerleri bulunduktan sonra, her parçacığın pozisyon ve hız bilgisi aşağıda verilen denklem (1) ve denklem (2) formülleri kullanılarak yeniden güncellenir (Azab, 2010). 


$$
\begin{gathered}
x_{i}(\mathrm{k}+1)=x_{i}(\mathrm{k})+V_{i}(\mathrm{k}+1) \\
V_{i}(\mathrm{k}+1)=w \cdot V_{i}(\mathrm{k})+c_{1} \cdot r_{1} \cdot\left[P_{\text {eniyi }}-x_{i}(\mathrm{k})\right]+c_{2} \cdot r_{2} \cdot\left[G_{\text {eniyi }}-x_{i}(\mathrm{k})\right]
\end{gathered}
$$

Denklem (1) ve denklem (2)'de; i parçacık sayısını, k tekrarlama sayısını, w atalet ağırlığını, $r_{1}$ ve $r_{2}$ değerleri sıfır ile bir arasında rastgele dağıtılmış olan değişken değerlerini, $\mathrm{c}_{1}$ ve $c_{2}$ hızlandırma katsayılarını, $P_{\text {eniyi }}$ i. parçacığın bulunduğu en iyi konum yerini, $\mathrm{G}_{\text {eniyi }}$ tüm popülasyon içerisindeki parçacıkların bulunduğu en iyi konum yerlerini, $x_{i}$ i. parçacığın konum yerini, $\mathrm{V}_{\mathrm{i}}$ ise i. parçacığın hız değerini belirtmektedir.

Global arama sonucunun en iyi çözüme yakınsamasını kontrol etmek amacıyla $\mathrm{c}_{1}, \mathrm{c}_{2}$ ve $\mathrm{w}$ değişkenleri kullanılır (Sagonda, \& Folly, 2019). Atalet ağırlığı olarak isimlendirilen w, yerel ve global arama işlemleri arasındaki dengeyi sağlamak amacıyla kullanılır ve sıfır ile bir arasındaki bir değer olarak ayarlanır (Azab, 2010). Hizlandırma katsayıları olan $\mathrm{c}_{1}$, parçacığın bilişsel öğesini, $c_{2}$ ise parçacığın sosyal öğesini etkiler. $\mathrm{Bu}$ iki öğe tarafından en uygun yakınsama işlemi gerçekleştirilir. Bu sebeple söz konusu bu iki öğenin doğru bir şekilde kontrol edilmesi oldukça önemlidir. Bilişsel öğe, popülasyondaki parçacıkların $\mathrm{P}_{\text {eniyi }}$ değerine doğru yönlenmesini sağlar. Sosyal öğe ise, parçacıkları belirlenen tekrarlama adımlarına kadar bulunacak olan en iyi global çözüm değerlerine doğru yönlendirir (Sagonda, \& Folly, 2019). Her bir parçacığın konumu bir uygunluk fonksiyonuyla değerlendirilir (Ahmed, \& Salam, 2013). Maksimum iterasyon sayısına ulaşıldığında PSO arama algoritması sonlandirılır (Teo, Lim, Chua, Goh, \& Tan, 2014).

\section{Sonuçlar ve Öneriler}

Günümüzde kullanılan PV enerji sistemleri yeni teknolojiler içermeleri nedeniyle oldukça yüksek maliyetlere çıkmaktadır. Güncel teknolojilerden faydalanılarak PV enerji sistemlerinin şebeke bağlantı yapıları gerçekleştirilir. Şebeke yapısının karmaşık olması ve sistemde karşılaşılacak olan olası zorluklar PV güneş panellerinden üretilen elektrik enerjisinin düşük seviyelerde olmasına neden olmaktadır. Bu nedenlerle PV enerji sistemlerinde maksimum güç noktası takibi yapılmakta ve elde edilecek olan verim değerinin yükseltilmesi hedeflenmektedir. Panel sıcaklığı, güneş 1şınım miktarı ve yük değişim değerlerine göre PV sistemlerin maksimum güç noktası değerleri değişkenlik göstermekte ve mutlaka takibi gerekmektedir. Özellikle PV enerji sistemlerinin doğrudan yüke bağlı olduğu durumlarda, PV sistemin maksimum güç noktasında çalışmadığı görülmektedir. Bundan dolayı, PV sistemin verimliliğini artırmak, PV panellerinden maksimum gücün elde edilmesini sağlamak amacıyla (MGNT) maksimum güç noktası takip yöntemlerinin kullanılması gerekmektedir.

$\mathrm{Bu}$ çalışmada, geçmişten günümüze PV enerji sistemleri hakkında yapılmış olan bilimsel çalışmalar incelenmiştir. Kompleks yapılı PV sistemlerdeki 1 şınım ve sicaklık değerlerinin enerji sistemi üzerindeki olası etkilerinden bahsedilmiştir. Kısmi gölgelenme şartları altındaki PV enerji sistemlerinin şebeke üzerindeki olumsuz etkileri hakkında bilgiler verilmiştir. Farklı topolojilere sahip DC-DC dönüştürücü devrelerinin kompleks yapılı PV enerji sistemleri ile birlikte tasarlanabileceğinden bahsedilmiştir. Maksimum güç noktası takip yöntemleri hakkında bilgiler verilmekte olup, geleneksel takip yöntemleri ile metasezgisel takip yöntemlerinin karşılaştırmalı analizi yapılmıştır. Ayrıca metasezgisel yöntemlerinden biri olan ve maksimum güç noktası takibinde yaygın olarak kullanılan PSO algoritması hakkında bilgiler verilmiştir. Kompleks yapıya sahip PV enerji sistemleri için gerekli olan maksimum güç noktası takibinin PSO algoritması kullanılarak yüksek doğruluk değerlerinde yapılabildiği gösterilmiştir. Bundan sonraki çalışmalarda hibrit yapıya sahip farklı tipteki metasezgisel algoritmalar kullanılarak PV enerji sistemlerinin maksimum güç noktaları takip edilebilir ve en verimli çalışma aralıkları belirlenebilir. Elde edilen bu değerler karşılaştırmalı olarak verilerek verim analizleri yapılabilir.

\section{Kaynakça}

Abo-Elyousr, F.K., Abdelshaf, M. \& Abdelaziz, A.Y. (2018). MPPT-based particle swarm and cuckoo search algorithms for PV systems. Modern Maximum Power Point Tracking Techniques for Photovoltaic Energy Systems, 379-400.

Ahmed, J. \& Salam, Z. (2013). A soft computing MPPT for PV system based on cuckoo search algorithm. $4^{\text {th }}$ International Conference on Power Engineering, Energy and Electrical Drives, Istanbul, 558-562.

Anoop, K. \& Nandakumar, M. (2018). A novel maximum power point tracking method based on particle swarm optimization combined with one cycle control. International Conference on Power, Instrumentation, Control and Computing (PICC), Thrissur, 1-6.

Aygül, K., Cikan, M., Demirdelen, T. \& Tumay, M. (2019). Butterfly optimization algorithm based maximum power point tracking of photovoltaic systems under partial shading condition. Energy Sources Part a Recovery Utilization and Environmental Effects, https://doi.org/10.1080/15567036. 2019.1677818

Azab, M. (2010). Optimal power point tracking for stand-alone PV system using particle swarm optimization. 2010 IEEE International Symposium on Industrial Electronics, Bari, 969-973.

Azharuddin, M. (2012). Effects of shading on the power of photovoltaic arrays. Purdue University, Yüksek Lisans Tezi.

Badis, A., Mansouri, M.N. \& Sakly A. (2016). PSO and GAbased maximum power point tracking for partially shaded photovoltaic systems. $7^{\text {th }}$ International Renewable Energy Congress (IREC), Tunisia.

Behera, T.K., Behera, M.K. \& Nayak, N. (2018). Spider monkey based improve P\&O MPPT controller for photovoltaic generation system. 2018 Technologies for Smart-City Energy Security and Power (ICSESP), Bhubaneswar, 1-6.

Benyoucef, A.S, Chouder, A., Kara, K., Silvestre, S. \& Sahed, O.A. (2015). Artificial bee colony based algorithm for maximum power point tracking (MPPT) for PV systems operating under partial shaded conditions. ELSEVIER, 3848.

Bholane, R.R. \& Babu P.S., (2018). Grid connected PV System using FB-PSO. International Conference on Smart Electric Drives \& Power System (ICSEDPS), doi:10.1109/ICSEDPS. 2018.8536065.

Charin, C., Ishak, D., Zainuri, M.A.A.M., Ismail, B. \& Jamil, M.K.M. (2021). A hybrid of bio-inspired algorithm based on levy flight and particle swarm optimizations for photovoltaic system under partial shading conditions. Solar Energy, 1-14.

Çetinbaş, I., Tamyürek, B. \& Demirtaş, M. (2019). Energy management of a PV energy system and a plugged-in electric vehicle based micro-grid designed for residential applications. $8^{\text {th }}$ International Conference on Renewable 
Energy Research and Applications (ICRERA), Brasov, Romania, 991-996.

Çetinbaş, I., Tamyürek, B., Demirtaş, M. (2019). Design, analysis, and optimization of a hybrid microgrid system using HOMER software: Eskişehir Osmangazi University Example. Int. Journal of Renewable Energy Development, 8(1): 65-79.

Dhivya, P. \& Kumar, K.R. (2017). MPPT based control of sepic converter using firefly algorithm for solar PV system under partial shaded conditions. International Conference on Innovations in Green Energy and Healthcare Technologies (IGEHT), Coimbatore, 1-8.

Esram, T. \& Chapman, P.L. (2007). Comparison of photovoltaic array maximum power point tracking techniques. IEEE Transactions on Energy Conversion, 439-449.

Fernando, M.O., Sergio, A.O. da Silva, Fábio, R. Durand \& Leonardo, P. Sampaio (2015). Application of PSO method for maximum power point extraction in photovoltaic systems under partial shading conditions. IEEE $13^{\text {th }}$ Brazilian Power Electronics Conference and 1st Southern Power Electronics Conference (COBEP/SPEC), Brazil.

Fang, G.J. \& Lian, K.L. (2017). A maximum power point tracking method based on multiple perturb-and-observe method for overcoming solar partial shaded problems. $\sigma^{\text {th }}$ International Conference on Clean Electrical Power (ICCEP), Santa Margherita Ligure, 68-73.

Gümüş, Z. \& Demirtaş, M. (2021). Fotovoltaik sistemlerde maksimum güç noktası takibinde kullanılan algoritmaların kısmi gölgeleme koşulları altında karşılaştırılması. Politeknik Dergisi, 24(3): 853 - 865.

Kaced, K., Larbes, C., Ramzan, N., Bounabi, M. \& Dahmane, Z.E. (2017). Bat algorithm based maximum power point tracking for photovoltaic system under partial shading conditions. Solar Energy, 490-503.

Kandemir, E. (2020). Kısmi gölgelenme koşullarında maksimum güç noktasında çalışan enerji geri kazanımlı tek dönüştürücülü şebeke bağlantılı PV sistem tasarımı ve uygulamas1. Ege Üniversitesi Fen Bilimleri Enstitüsü, Doktora Tezi, İzmir, 1-2-10-47.

Karaboğa, D. (2011). Yapay zekâ optimizasyon algoritmalar1. Nobel Yayınlart, ISBN 978-605-395-434-7, 18.

Karagöz, M.K. (2020). FV sistemler için kısmi gölge koşullarını yönetebilen yarasa algoritması tabanlı maksimum güç noktası izleyici tasarımı ve gerçekleştirilmesi. Karabük Üniversitesi Lisansüstü Eğitim Enstitüsü, Doktora Tezi, Karabük, 2.

Karakaya, H.B. (2021). Fotovoltaik sistemlerde maksimum güç noktasının takibi için kullanılan optimizasyon algoritmalarının performansının değerlendirilmesi. Kahramanmaraş Sütçü Imam Üniversitesi, Fen Bilimleri Enstitüsü, Yüksek Lisans Tezi, Kahramanmaraş, 21.

Kennedy, J. \& Eberhart, R. (1995). Particle Swarm Optimization. IEEE International Conferenceon Neural Networks, Perth, Australia, IEEE Servive Center, Piscataway, NJ, 1942-1948.

Liu, G., Zhu, J., Tao, H., Wang, W. \& Blaabjerg, F. (2019). A MPPT algorithm based on PSO for PV array under partially shaded condition. $22^{\text {nd }}$ International Conference on Electrical Machines and Systems (ICEMS), Harbin, China, 1-5.

Manickam, C., Raman, G.R., Raman, G.P., Ganesan, S.I. \& Nagamani, C. (2016). A hybrid algorithm for tracking of gmpp based on $\mathrm{P} \& \mathrm{O}$ and $\mathrm{PSO}$ with reduced power oscillation in string inverters. IEEE Transactions on Industrial Eelctronics, 63: 6097-6106.

Miyateke, M., Verachary, M., Toriumi, F., Fujii, N. \& Ko, H. (2011). Maximum power point tracking of multiple photovoltaic arrays: A PSO Approach. IEEE Transactions on Aerospace and Electronic Systems, 47 (1): 367-380.

Motamarri, R. \& Nagu, B. (2020). GMPPT by using PSO based on levy flight for photovoltaic system under partial shading conditions. IET Renewable Power Generation, 1143-1155.

Nugraha, D.A., Lian K.L. \& Suwarno (2019). A novel MPPT method based on cuckoo search algorithm and golden section search algorithm for partially shaded pv system. Canadian Journal of Electrical and Computer Engineering, 42:173-182.

Safari, A. \& Mekhilef, S. (2011). Simulation and hardware implementation of incremental conductance MPPT with direct control method using cuk converter. IEEE Trans. Ind. Electron, 1154-1161.

Sagonda, A.F. \& Folly, K.A. (2019). Maximum power point tracking in solar PV under partial shading conditions using stochastic optimization techniques. IEEE Congress on Evolutionary Computation (CEC), Wellington, New Zealand, 1967-1974.

Santos, J.L., Antunes, F., Chehab, A. \& Cruz, C. (2006). A maximum power point tracker for FV systems using a high performance boost converter. Solar Energy, 772-778.

Shaiek, Y., Ben Smida, M., Sakly, A. \& Mimouni, M.F. (2013). Comparison between conventional methods and GA approach for maximum power point tracking of shaded solar PV generators. Solar Energy, 107-122.

Sun, Y., Lou, Z., Xi, Z., Bao, Z., Li, X. \& Yan, W. (2018). Composite MPPT control algorithm with partial shading on $\mathrm{PV}$ arrays. IEEE $4^{\text {th }}$ Information Technology and Mechatronics Engineering Conference (ITOEC), Chongqing, China, 898-902.

Suryavanshi, R., Joshi, D.R. \& Jangamshetti, S.H. (2012). PSO and $\mathrm{P} \& \mathrm{O}$ based MPPT technique for spv panel under varying atmospheric conditions. International Conference on Power, Signals, Controls and Computation, Kerala, 1-6.

Teo, K.T.K., Lim, P.Y., Chua, B.L., Goh, H.H. \& Tan, M.K. (2014). Maximum power point tracking of partially shaded photovoltaic arrays using particle swarm optimization. $4^{\text {th }}$ International Conference on Artificial Intelligence with Applications in Engineering and Technology, Kota Kinabalu, 247-252.

Ünlü, M. (2015). Fotovoltaik sistemler için parçalı gölgelenme durumlarında maksimum güç noktası izleyebilen şebeke bağlantılı yeni bir evirici tasarımı ve uygulaması. Kocaeli Üniversitesi Fen Bilimleri Enstitüsü, Doktora Tezi, Kocaeli. 